Case Report

\title{
Reconstruction sequence and microsurgery in ectrodactyly-ectodermal dysplasia-cleft lip/palate syndrome: a case report
}

\author{
Jorge Gaviria-Pinzon*, Jhon Gutierrez Q., Luis Bermudez R., Luis Nieto R.
}

\begin{abstract}
Department of Plastic and Reconstructive Surgery, Central Military Hospital, Nueva Granada Military University, Bogota, Colombia
\end{abstract}

Received: 01 January 2022

Accepted: 18 January 2022

\section{*Correspondence:}

Dr. Jorge Gaviria-Pinzon,

E-mail: jorgegaviria10@gmail.com

Copyright: ( $)$ the author(s), publisher and licensee Medip Academy. This is an open-access article distributed under the terms of the Creative Commons Attribution Non-Commercial License, which permits unrestricted non-commercial use, distribution, and reproduction in any medium, provided the original work is properly cited.

\begin{abstract}
Ectrodactyly-ectodermal dysplasia-cleft lip/palate syndrome (EEC), is a rare entity characterized by alterations in the skin, hair, nails, apocrine glands and teeth, associated with dimorphisms in extremities and midface dysplasia. It is attributed to a mutation in the p63 gene. These patients require multiple surgical procedures to achieve functional goals. We present the surgical sequence of the interdisciplinary management performed on a patient diagnosed with this syndrome and the functional results obtained. A 5 months old female patient presented to our service with a suspected EEC syndrome. We present the case and the surgical procedures performed to achieve functional results. EEC syndrome is a low frequency patology which requires specialized surgical procedures of different kinds. Different surgical methods and techniques should be considered, due to the number and complexity of the malformations, which is why all human and technical resources must be available for its proper treatment.
\end{abstract}

Keywords: Ectrodactily, Ectodermic dysplasia, Cleft lip, Cleft palate, Lobster hand

\section{INTRODUCTION}

Ectrodactyly-ectodermal dysplasia-cleft lip/palate syndrome (EEC syndrome), is a rare entity characterized by alterations in the skin, hair, nails, apocrine glands and teeth, associated with dimorphisms in extremities and midface dysplasia. ${ }^{1}$

To date, approximately 300 cases have been reported in the literature, and it is attributed to a mutation in the p63 gene, which leads to a blockage in cell signaling that does not allow adequate interaction between the ectoderm and the mesenchyme, resulting in abnormal morphogenesis. ${ }^{1-3}$

In the surgical management of these patients, even when the procedures performed may be like their nonsyndromic presentations, the presence of ectodermal dysplasia increases the risk of complications, and it may be necessary to perform multiple additional secondary procedures to achieve the desired functional goals. ${ }^{1}$
We present the surgical sequence of the interdisciplinary management performed on a patient diagnosed with this syndrome and the functional results obtained.

\section{CASE REPORT}

A female patient with prenatal diagnosis of cleft lip and palate by ultrasonography, pregnancy of 39 weeks of gestation, birth by cesarean section.

On physical examination, she presented a right unilateral cleft lip and a complete cleft palate (Figure 1), complete syndactyly between first and second finger, with agenesis of the third finger in the right hand (Figure 2), agenesis of the middle and distal phalanx of the second left toe, hypoplasia of first and second metatarsals, agenesis of the second and third toes, hypoplasia and clinodactyly of the right first toe (Figure 3). She was evaluated by the clinical genetics service, who suspected that the patient had clinical findings of EEC syndrome and requested 
TP63 gene sequencing, being positive for variant c.952c> $\mathrm{T}$ (p. Arg318Cys) confirming the diagnosis.

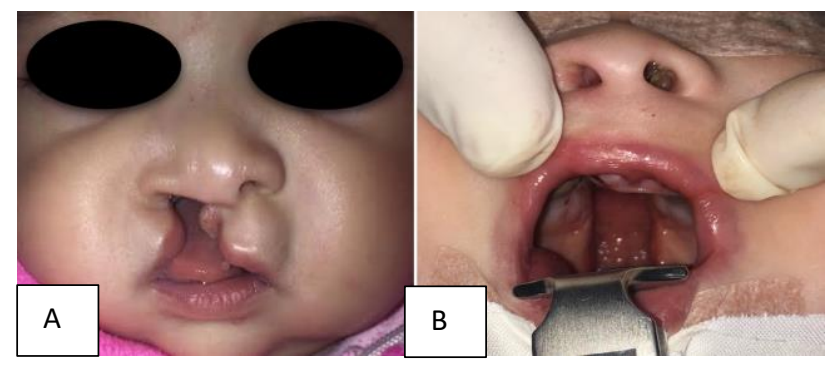

Figure 1 (A and B): Cleft lip and palate.

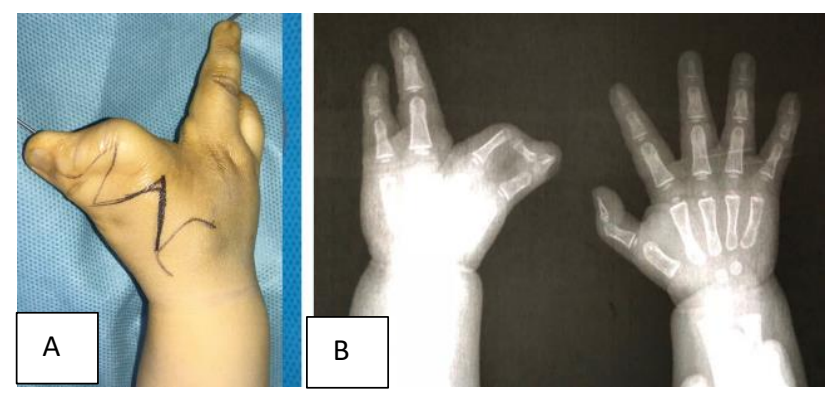

Figure 2 (A and B): Syndactyly of the $1^{\text {st }}$ and $2^{\text {nd }}$ finger, and agenesis of the $3^{\text {rd }}$ finger of the right hand.

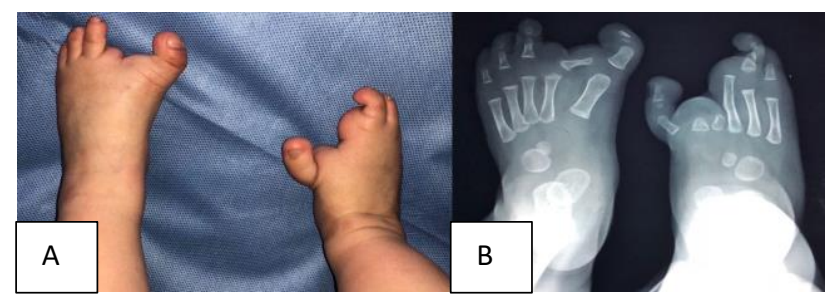

Figure 3 (A and B): Ectrodactyly in the feet.

At 5 months of age, a right unilateral cheiloplasty was performed with the modified Millard technique, 5 months later a palatorrhaphy was performed with the Bardach technique.

At 21 months, limb malformations were corrected: in the left foot, resection of the 2 nd ray and closure of the interdigital space: Taking advantage of the excesive skin, a free skin flap was designed based on the 1st dorsal metatarsal artery, in order to transfer it to the right hand, and a tendon transfer of the extensor of the remnant of the second toe to the hallux to correct its wrong position (Figure 4).

In the right foot, a capsulotomy of the first metatarsal and osteotomy of the third was done to close the cleft due to agenesis of the $2^{\text {nd }}$ and $3^{\text {rd }}$ fingers (Figure 5).

In the right hand, correction of syndactyly and release of the first interdigital space, with a resultant significant deficit of skin to be covered, for which a previously raised free skin flap was transferred from the left foot, performing microsurgical anastomoses to radial vessels (Figure 6).

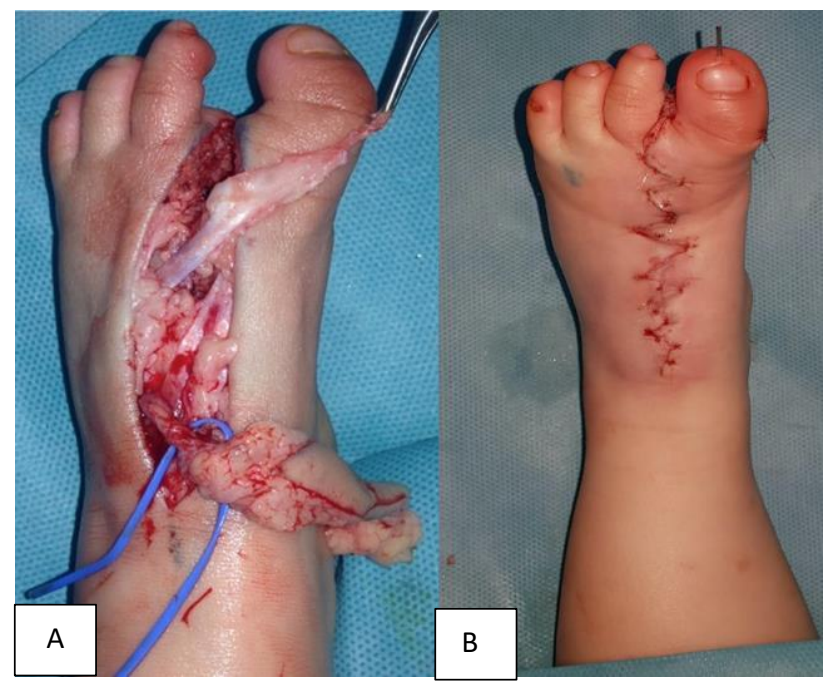

Figure 4 (A and B): Resection of the $2^{\text {nd }}$ ray, dorsal skin flap and tendinous transfer in the left foot.

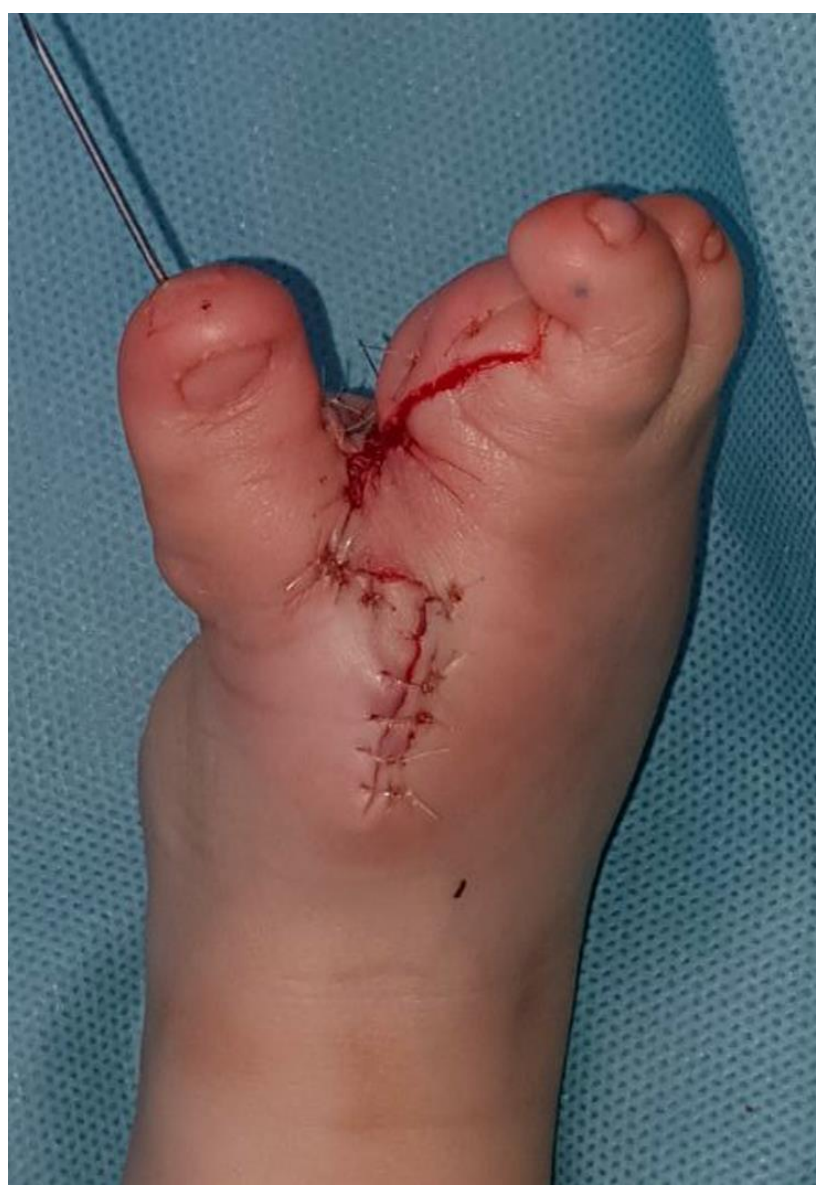

Figure 5. Closure of the cleft and correction of clinodactyly in the right big toe.

In the postoperative controls, adequate healing of the lip and palate and the achievement of functional objectives 
with and adequate gait and use of the right hand in daily activities was evidenced (Figure 7).

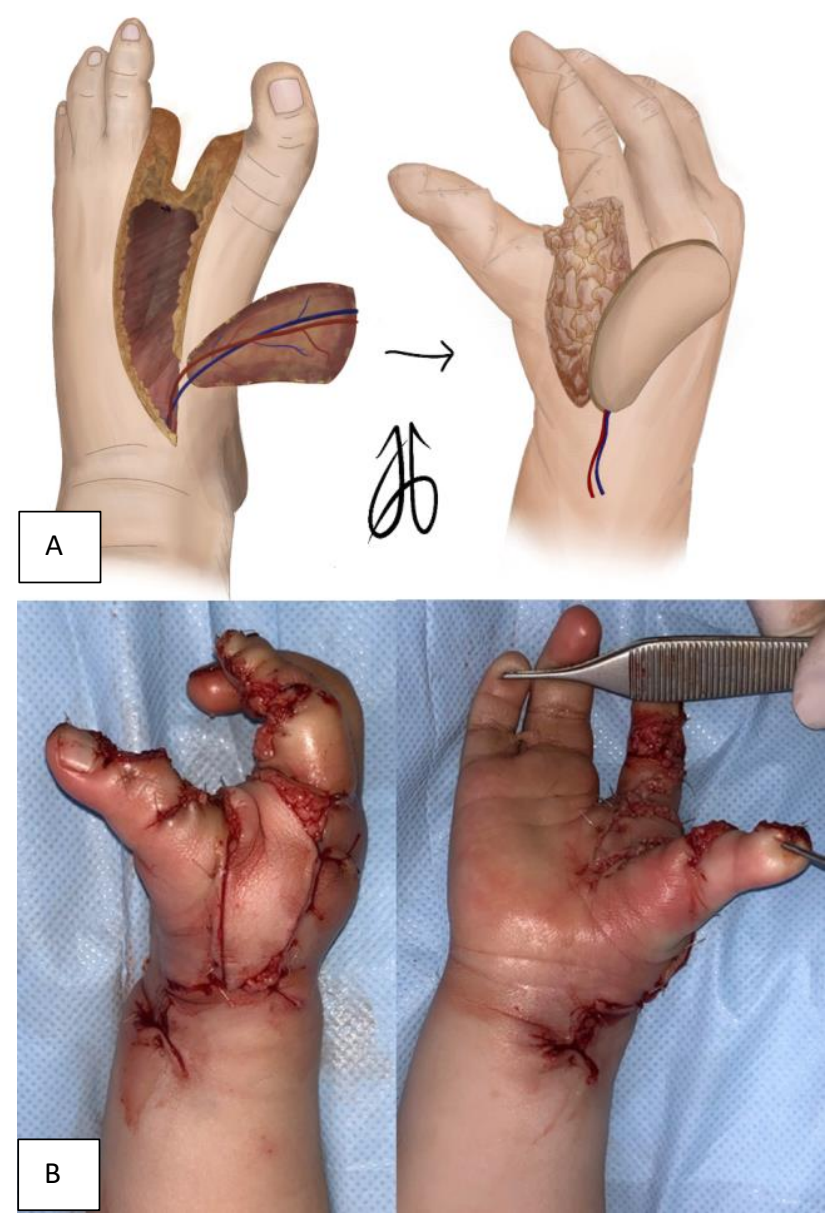

Figure 6 (A and B): Syndactyly release and reconstruction of the $1^{\text {st }}$ web space with a dorsalis pedis skin free flap.

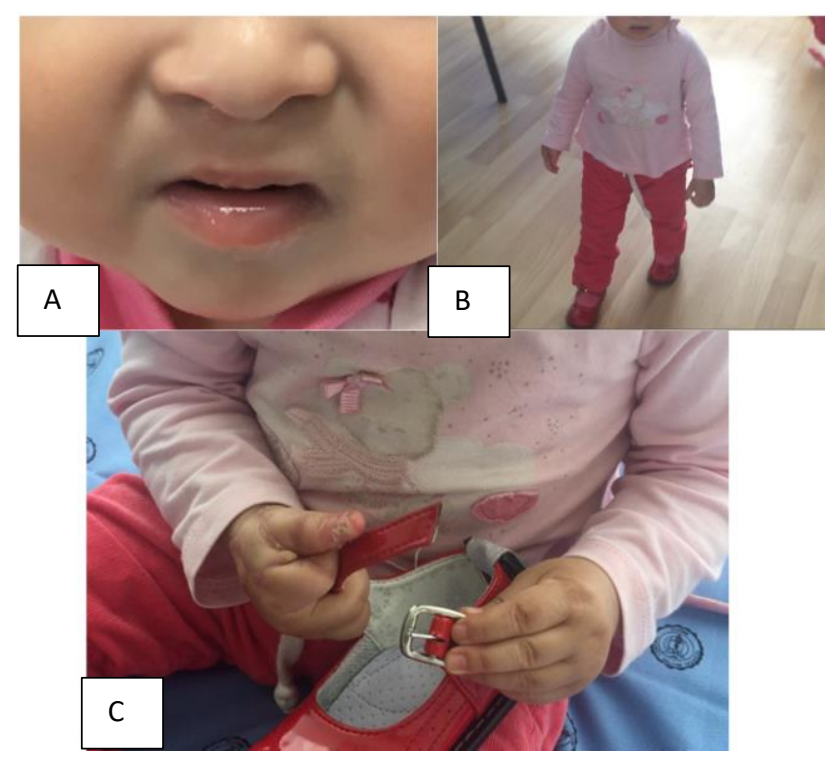

Figure 7 (A-C): Post operative results

\section{DISCUSSION}

The EEC syndrome is a congenital disease of an autosomal dominant nature, with low penetrance and variable expressiveness, with an approximate incidence of 1/50,000 live births. ${ }^{4}$ The first case of a patient with ectrodactyly was described by Eckholdt and Martens in 1804, but it was not until 1970 that Rudiger et al coined the name. ${ }^{5}$

In $98 \%$ of the patients, a heterozygous mutation has been identified in the expression of the TP63 protein, also known as p63, which produces a blockage in the signaling pathway of nuclear factor kappa-beta that affects the interaction between the ectoderm and the mesoderm, thus leading to an alteration of normal morphogenesis. ${ }^{6}$ The $50 \%$ of the cases occur by inheritance, in the others by spontaneous mutations. There are two forms of presentation of the entity, the first with a cleft lip with or without affection of the palate and the second only with a cleft palate.

Ectodermal dysplasia groups more than 200 entities, finding an abnormal development of at least two tissues derived from the embryonic ectoderm. ${ }^{7}$ Patients present with thin skin with hyperkeratosis foci, scant hair, thin and hypopigmented hair, anodontia, hypodontia or absence of tooth enamel, and apocrine gland alterations may be present. ${ }^{8}$

Ectrodactyly also known as lobster claw hands and feet affects $85 \%$ of patients. $^{9}$ It is pathognomonic of the disease and is characterized by absence of the $3^{\text {rd }}$ ray and syndactyly between the $1^{\text {st }}-2^{\text {nd }}$ and the $4^{\text {th }}-5^{\text {th }}$ finger. It may present in a typical way (Type I) with the absence of one or two medial rays, with rays surrounding the fissure with normal appearance, or type II or atypical with all rays affected. ${ }^{10}$ Syndactyly can be incomplete or complete if it reaches the distal phalanges, simple or complex if it presents bone fusion between the fingers, or complicated if it is associated with another abnormality such as polydactyly, symphalangism, brachydacytlia, or compromises muscle-tendon or neurovascular boundle. ${ }^{11}$

Cleft lip/palate is present in $86 \%$ of patients. A complete and wide cleft lip, protrusion of the premaxilla, hypoplasia of the columella and hypoplastic pro-lip are usually present. Maxillary hypoplasia is found as a consequence of ectodermal dysplasia, especially due to dental alterations which make orthodontic and orthognathic procedures difficult. ${ }^{12}$

Other frequently encountered findings are alterations in the lacrimal tract that can lead to corneal ulceration, keratitis, blepharitis, blindness, alterations of the genital tract and hearing loss. ${ }^{13}$

For cleft lip/palate correction, complications may occur more frequently due to the multiple factors that affect the oral cavity, such as decreased salivation, missing teeth, 
and cavities intensified by the absence of enamel. The correction of the hands and feet is aimed at functional improvement, rather than aesthetics, correcting cleft and digital deformities. ${ }^{11}$ The correction of the deformity in the hands is also aimed at achieving an anatomical orientation that allows an adequate grip. Netcher et al propose objectives that allow the above, seeking to maintain a thumb and at least two ulnar fingers that allow fine dexterity, or at least one of the radial or ulnar fingers mobile with a stable opposition, and achieve, as far as possible, a good sensitivity of fingertips. ${ }^{14}$

Horta et al propose an algorithm that allows selecting the most viable free flap according to the defect to be repaired likewise Javaid et al reported a series of cases where simple and compound free flaps were used to cover bloody areas on the back of the hands, obtaining good results. ${ }^{15,16}$

In this clinical case, a patient with EEC syndrome is described, who presents multiple of its clinical characteristics and a confirmed diagnosis by genetic sequencing. A previously planned sequence of multiple surgical procedures were performed by a multidisciplinary team, obtaining good functional and aesthetic results.

\section{CONCLUSION}

The EEC syndrome is an entity that occurs with low frequency. It requires specialized surgical procedures of different kinds, where possible complex anatomical alterations must be considered for its reconstruction and the higher incidence of complications due to ectodermal dysplasia.

Different surgical methods and techniques should be considered, due to the number and complexity of the malformations, which is why all human and technical resources must be available for its proper treatment.

Funding: No funding sources

Conflict of interest: None declared

Ethical approval: Not required

\section{REFERENCES}

1. Wojcicki P, Wysocki M, Wojcicka K. Ectrodactylyectodermal dysplasia-clefting syndrome-plastic surgeon's considerations. J Craniofac Surg. 2010;21(5):1388-92.

2. Koul M, Dwivedi R, Upadhyay V. Ectrodactylyectodermal dysplasia clefting syndrome (EEC syndrome). J Oral Biol Craniofacial Res. 2014;4(2):135-9.
3. Barrow LL, Van Bokhoven H, Daack-Hirsch S, Andersen T, Van Beersum SE, Gorlin R et al. Analysis of the p63 gene in classical EEC syndrome, related syndromes, and non-syndromic orofacial clefts. J Med Genet. 2002;39(8):559-66.

4. Raoul CM, Hennekam, Krantz ID, Allanson JE. Gorlin's Syndromes of the Head and Neck. $5^{\text {th }}$ ed. Oxford; 2001;828-81.

5. Rudiger R, Haase W, Passarge E. Association of Ectrodactyly, Ectodermal Dysplasia, and Cleft LipPalate. The EEC Syndrome. Am J Dis Child. 1970;120:160-3.

6. Brunner HG, Hamel BC, Van Bokhoven H. The p63 gene in EEC and other syndromes. J Med Genet. 2002;39(6):377-81.

7. Rinne T, Brunner HG, Van Bokhoven H. p63associated disorders. Cell Cycle. 2007;6(3):262-8.

8. Kelman GJ, Aronoff RC. Ectrodactyly-Ectodermal Dysplasia-Clefting Syndrome. J Am Podiatr Med Assoc. 2000;460-4.

9. Van Bokhoven H. p63 Gene mutations in eec syndrome, limb-mammary syndrome, and isolated split hand-split foot malformation suggest a genotype-phenotype correlation. Am J Hum Genet. 2001;69(3):481-92.

10. Ianakiev P, Kilpatrick MW, Toudjarska I, Basel D, Beighton P, Tsipouras P. Split-hand/split-foot malformation is caused by mutations in the p63 gene on 3q27. Am J Hum Genet. 2000;67(1):59-66.

11. Tani Y, Ikuta Y, Ishida O. Surgical Treatment of the Cleft Foot. Plast Reconstr Surg J. 2000;105(6):19972002.

12. Ganske IM, Irwin T, Langa O, Upton J $3^{\text {rd }}$, Tan WH, Mulliken JB. Cleft Lip and Palate in Ectodermal Dysplasia. Cleft Palate Craniofac J. 2021;58(2):23743.

13. Mawhorter LG, Ruttum MS, Koenig SB. Keratopathy in a family with the ectrodactylyectodermal dysplasia-clefting syndrome. Ophthalmology. 1985;92(10):1427-31.

14. Netscher D, Baumholtz M. Treatment of Congenital Upper Extremity Problems. Plast Reconstr Surg J. 2007;119(5):101-29.

15. Horta R, Silva P, Costa-ferreira A, Amarante J, Silva A. Microsurgical Soft-Tissue Hand Reconstruction : An Algorithm for Selection of the Best Procedure. J Hand Microsurg. 2011;3(2):73-7.

16. Javaid M, Cormack G. Anterolateral Thigh Free Flap for Complex Soft Tissue Hand reconstructions. J Hand Surg Am. 2003;28B(1):21-7.

Cite this article as: Gaviria-Pinzon J, Gutierrez J, Bermudez L, Nieto L. Reconstruction sequence and microsurgery in ectrodactyly-ectodermal dysplasiacleft lip/palate syndrome: a case report. Int Surg J 2022;9:467-70. 